\title{
Determining management preferences in a multimethod consumptive recreational fishery
}

\author{
Mary Mackay $^{1,2}$, Satoshi Yamazaki ${ }^{1,2}$, Jeremy M. Lyle $^{3}$ and Emily M. Ogier $^{2,3}$
}

\begin{abstract}
Understanding behavioral responses of recreational fishers to management changes is fundamental for effective policy making. However, given the diverse motivations and nonmarket nature of recreational fishing, evaluating fishers' preferences is nontrivial. This study examined fishers' management preferences toward different management tools (i.e., a new measure or a change in the setting for an existing measure) in a highly consumptive recreational fishery. A combination of a discrete choice experiment and an opinion-based survey explored the potential heterogeneity in management preferences in the Tasmanian Rock Lobster fishery. Although the fishery has extensive management in place, further restrictions are required to limit recreational harvest in support of a strategy to achieve a stock rebuilding target. As a diverse fishery, with various fishing methods and a range of activity levels, it is expected that the perceptions of management changes vary across fisher subgroups. A phone survey was used to ask fishers' opinions on how effective different management tools are at restricting catch and if they supported or opposed the tool. Additionally, a discrete choice experiment was used to assess if fishers' utility is associated with a management tool and to what extent fishers are willing to trade a change in one management tool for a change in another. Results show that there are both homogenous and heterogeneous management preferences in the fishery across fisher subgroups. There was consensual aversion by all fisher subgroups toward changes in management settings that directly limit the catch of lobster, including a reduction in daily bag limit and shortened season length. Other changes to management settings, such as an increase in the minimum size limit, have less consensus in preference between fisher groups, and any changes in these tools could differentially impact fisher subgroups. The results from this research can support managers in identifying whether and to what extent intra-sector separation for the purposes of designing and implementing new management measures and settings is warranted, on the basis that it can increase effectiveness of achieving management and the likelihood of maximizing net utility within a fishery.
\end{abstract}

Key Words: discrete choice experiment; management preferences; recreational fishers

\section{INTRODUCTION}

Given the rising pressures on fish stocks and multiple benefits generated by recreational fishing, the need for responsible and sustainable recreational fisheries is increasingly recognized (van Putten et al. 2017, Cooke et al. 2019). There is a myriad of policy options and objectives for the management of recreational fisheries with varying effectiveness in aspects such as fisher enjoyment, compliance, and stock sustainability. Successful fishery management depends on whether it accounts for various sources of uncertainty, including variability in resource dynamics (Hofmann and Powell 1998), uncertainties concerning catch reporting, monitoring and assessment (Agnew et al. 2009), and even politicized management decisions (Tsangarides 2007). Recreational fisheries, however, are managed for participation and amenity, and these can be countervailing when amenity is primarily derived from consumption as is the case in highly consumptive fisheries. Overfishing, lack of effective management, and consequences of climate change in high value recreational species, such as abalone, tuna, and rock lobster, has caused the biological sustainability of these stocks in Australian waters to be under pressure (Hobday et al. 2011). Specifically, fishers behaving contrary to management intentions is a consistent factor contributing to the divergence between the intended and actual management outcomes, contributing to ineffective management (Fulton et al. 2011).

To anticipate behavioral responses to planned management changes, an acute understanding of fishers' motivations to participate in the recreational fishery as well as their preferences toward different management tools is necessary. A management tool can be a new measure (e.g., tag system) or a change in the setting for an existing measure (e.g., reduce bag limit). Specifically, in high value fisheries, there is often a large and diverse population of recreational fishers with subgroups forming based on similarity of behaviors or preferences. Therefore, managers are required to trade off the effectiveness of management alternatives on constraining catches (i.e., fishers' responses to planned management changes) and the effects on population-wide utility and subgroup utility (Bess and Rallapudi 2007). These subgroups tend to have different behaviors and preferences, consequently management interventions will have differing impacts in terms of amenity and management effectiveness. Understanding the degree and significance of heterogeneity within a recreational fishery allows policymakers to be informed of distributional effects and to determine whether to manage for the recreational fisher population as a whole, or for a series of subpopulations with different utility preferences and behavioral drivers. It is useful to identify subgroups based on distinct behaviors and preferences, such as for-hire or private anglers (Doerpinghaus et al. 2014), or fishing mode within a multimethod fishery because this allows clear distinctions for the purposes of group identification and management. Characteristics such as expert specialization or high avidity (Scott and Shafer 2001) are important to consider because these fishers have greater direct impact on the resources. Generally, it is unadvisable to reduce the preferences of

${ }^{1}$ Tasmanian School of Business and Economics, University of Tasmania, Hobart, ${ }^{2}$ Centre for Marine Socioecology, University of Tasmania, Hobart, ${ }^{3}$ Institute for Marine and Antarctic Studies, University of Tasmania, Hobart 
heterogeneous fisher populations to homogenous ones that represent an average fisher (Matsumura et al. 2019).

Recreational fisheries management has tended to reflect commercial fisheries management, yet the motivations of fishers vary between the two. As opposed to commercial fisheries in which motivations are predominantly related to economic rewards, motivations vary extensively for recreational fishers (Fedler and Ditton 1994, Cooke et al. 2019). Broadly, recreational fishers can engage in either catch-and-release fishing (i.e., nonconsumptive) or harvest-orientated fishing (i.e., consumptive; Yamazaki et al. 2011, Cooke et al. 2019). However, beyond this dichotomy the motivations become more complex. These motivations include psychological and physiological benefits, such as spending time in natural environments, social engagements with others, a fishery/food resource, and engaging and overcoming skill and equipment challenges (Fedler and Ditton 1994). Although there is a plethora of research on fisher behavior (Duttweiler 1976, Renyard and Hilborn 1986, Matlock et al. 1988, Teisl et al. 1993, Aas and Skurdal 1996, Fulton et al. 2011, Stoop et al. 2012, Hoshino et al. 2017), the link between these motivations and responses to management are not always considered by fisheries scientists or managers (Fulton et al. 2011).

Given the diverse motivations and nonmarket nature of recreational fishing, evaluating fishers' preferences toward different management tools is nontrivial. Two approaches that are commonly used to elicit the preferences of heterogenous recreational fisher populations are (1) fisher surveys to obtain self-reported measures of management preferences, and (2) discrete choice experiments (DCEs). For example, previous fisher surveys have identified heterogeneous preferences of recreational fishers who are categorized by residence (urban/rural fishers; Arlinghaus and Mehner 2004), association to fishing locality (residents/ nonresidents; Teisl et al. 1993), water type (marine/ freshwater; Frijlink and Lyle 2010), and avidity level (Frijlink and Lyle 2010, Mcllgorm et al. 2016). Discrete choice experiments have also been used to categorize fishers' preferences across specialization (Beardmore et al. 2013) and fishing method (Aas et al. 2000). A major difference between the two approaches is that fisher surveys directly ask respondents to self-report their perceptions of each management tool in question, whereas DCEs force respondents to consider different management tools simultaneously and account for trade-offs between them. The dual methodology may be advantageous because the use of both enables one to determine fishers' preferences and opinions on different management tools for comparable samples of fishers. We expect that each methodology may have unique advantages to identify the levels of utility between fisher subgroups, however, such an application is limited in the literature.

The aim of this study is to identify the range and diversity of motivations and expected behaviors of recreational fishers in response to potential management changes and to what extent fishers are willing to accept trade-offs between different management tools in a highly consumptive multimethod fishery. Specifically, we explored potential heterogeneity in responses among fishers with different avidity levels and fishing methods. Avidity has been linked to specialization (Han and Oh 2018) and centrality to fishing lifestyle (Mcllgorm et al. 2016). Although avidity can be measured in different ways, such as commitment to the activity (i.e., willingness to substitute for another activity) or investment in fishing (Ditton and Sutton 2004), avidity is typically measured based on number of days fished per season. In this study, fishing method used by fishers was applied as a proxy for fishers' differing in motivations or attitudes because Lyle (2018) found that mode of fishing in the Tasmanian rock lobster fishery has been shown to have a strong influence on catch rates, catch size selectivity, and fisher behavior (in particular effort levels and fishing strategies). It is likely that preferences are more complex and heterogeneous within a multigear fishery than in single-gear fishery because motivations will vary based on the fishing activity itself relative to harvest motivations.

To achieve our research aims, we conducted a phone survey and a DCE for the current license holders in the Tasmanian east-coast recreational rock lobster fishery. The phone survey sought fishers' opinions on how effective different management tools are at restricting catch, and whether they would be supportive of the tool. Additionally, the DCE was used to assess if fishers' utility is associated with a management tool and to what extent fishers are willing to trade off a change in one management tool for a change in another tool. The fishery has extensive management in place, such as separate fishing licenses required for different fishing methods, bag limits, and seasonal closures, with on-going discussion around the need for management action to further constrain recreational harvest to within rebuilding target levels. Therefore, changes to the management are not solely a hypothetical scenario. In the Tasmanian east-coast recreational rock lobster fishery, the stocks have been in decline, and consequently, a 10-year strategy was implemented in 2013 to rebuild them to healthy levels. To achieve this, measures to limit the number of lobsters caught were implemented for the recreational sector, but it was later found that further restrictions are required to meet and sustain the stock rebuilding goals (see Box 1 for more details). As a diverse fishery, with fishers collecting lobsters via diving, pots, and rings as well as broad avidity levels, there is an urgent need to identify fishers' preferences toward different management tools and to identify which groups of fishers would be most affected by any future management changes.

\section{Box 1:}

Case study fishery. The southern rock lobster (Jasus edwardsii) is highly prized within Tasmania, Australia, by both recreational and commercial fishers. During the 2017-2018 season (November 2017-April 2018) 17,200 people held at least one recreational rock lobster license (Lyle 2018). They are fished using pots, ring nets, and through dive collection, and annual licenses are required to use each of these methods to fish recreationally. During the 2017-2018 season, licensed recreational fishers were estimated to have harvested roughly 72,000 lobster, based on 77,209 fisher days of effort, with potting being the dominant fishing method used. The rock lobster fishery was concentrated off the east coast of Tasmania with this area accounting for $70 \%$ of the harvest (Lyle 2018). There are daily bag limits, boat limits, and possession limits in place as well as size limits, closed seasons, and a total ban on taking females carrying eggs (Lyle 2018).

In the 2005 management review of the Tasmanian rock lobster fishery, provision was made for an explicit catch allocation to the 
recreational sector. More recent concerns over the status of the east coast rock lobster stocks resulted in the implementation a 10-year plan (2013-2023) to rebuild east coast stocks to greater than $20 \%$ of unfished biomass (DPIPWE 2018). The rebuilding strategy seeks to limit the total rock lobster catch from the east coast to 200 tonnes and is based on a notional resource sharing arrangement of $21 \%$ for the recreational sector (42 tonnes) and $79 \%$ for the commercial sector ( 158 tonnes). Key elements of the rebuilding strategy relevant to recreational fishers involved dividing Tasmania into eastern and western rock lobster fishing regions (Fig. 1), reducing eastern region bag and possession limits and delaying the opening of the eastern region fishery. Given a positive correlation between recreational participation and catch (Lyle 2018), the number of license holders is expected to increase along with an increase in the stocks in response to the stock rebuilding efforts. Because there is currently no limit on the number of recreational license holders, further restrictions on catch or effort are likely required to curtail increasing pressures on the stock.

Fig. 1. Map showing Tasmanian Australian statistical geography standard statistical areas rock lobster fishing regions and the current (2019) east coast stock rebuilding zone. Map taken from (Lyle 2018).

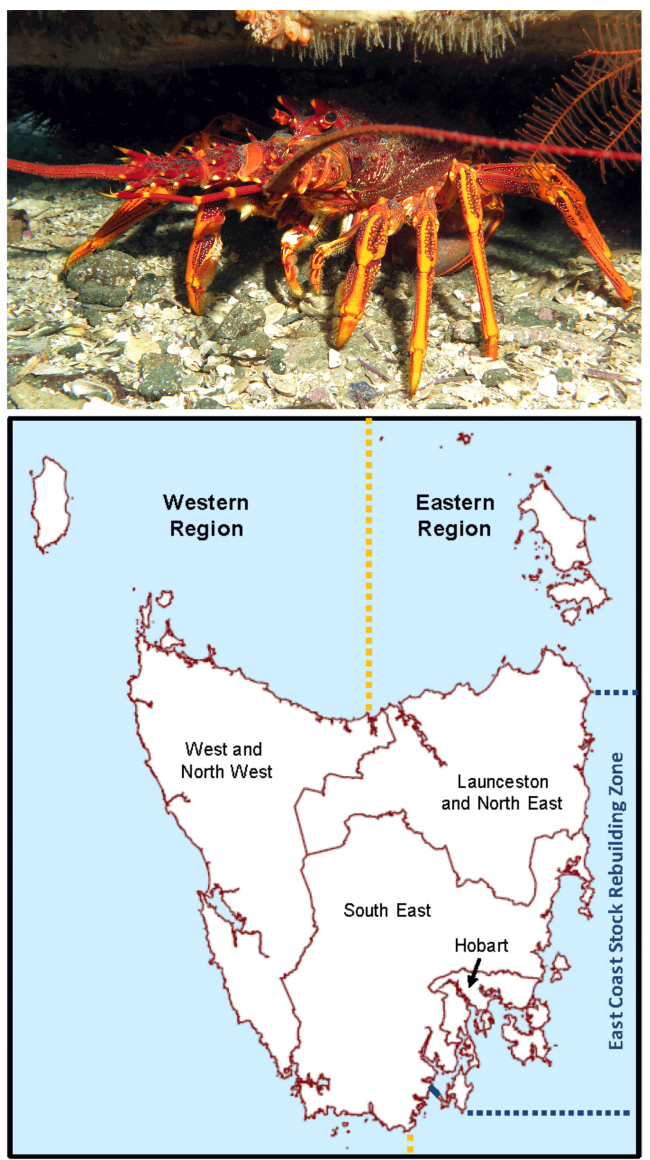

\section{METHODS}

\section{Phone survey}

The phone survey involved a random sample of recreational rock lobster license holders and was focussed on license holders aged 18-years and older who resided in Australian Bureau of Statistics regions (level SA4) that border the east coast of Tasmania. From a total sample of 729 license holders for whom phone contact details were available, contact was made with 674, with $570(78 \%$ of the net sample) responding to the survey. The phone survey was conducted between May and June 2018.

Using a structured questionnaire, fishers' opinions regarding a range of fishery and management issues were surveyed. Specific questions relevant to this study focussed on the respondents' perceptions regarding whether specific management tools would be effective in restricting the recreational rock lobster harvest, and whether they would generally be supportive of the option, on the understanding that there was a need to limit the rock lobster harvest to allow for stock rebuilding. Six management tools were presented; (1) reduction in the recreational bag limit from two to one lobster per day, (2) increase in the minimum size limit (to ensure more of the catch is released), (3) reduction in season length, (4) introduction of an individual seasonal catch limit, (5) limit on the number of recreational licenses issued, and (6) reduction in the commercial catch allowance to offset for any increase in recreation catch. For each respondent, the rock lobster license(s) held (pot, dive, and/or ring) was known, enabling individuals to be classified based on fishing mode (pot, dive, or multimode). In addition, each respondent was classified based on their avidity (days fishing for rock lobster). Approximately 59\% of the respondents (334 persons) had completed a diary-based survey of their rock lobster fishing during the 2017/18 fishing season (Lyle 2018) prior to undertaking the phone survey. This provided an estimate of days fished (avidity) for each respondent. For the remaining respondents (236 persons), reported days fished for rock lobster during 2017/18 was based on recalled information.

Phone survey respondents who indicated that they usually fished off the east coast, the stock rebuilding region, were deemed eligible to participate in the follow-up DCE survey. In total, 307 phone survey respondents agreed to do the DCE either via mail or an online platform (104 requested mail surveys and 203 requested online surveys). The online and mail surveys were conducted between May to October 2018, and 156 completed DCEs were received (51 mail and 105 online).

\section{Discrete choice experiment}

\section{Conceptual framework}

Discrete choice experiments (DCE) are a survey-based stated preference approach that can elicit respondents' preferences for a good in question, such as preferences for different management tools. The DCE evolved from Lancaster's (1966) theory of consumer behavior, in which the utility derived from an alternative is associated with the attributes of the alternatives. In DCE, the utility of alternatives is characterized based on the assumption that respondents choose the alternative that provides the greatest utility for them (Adamowicz et al. 1998). Specifically, our analysis relies on a random utility model, in which $U_{n s j}$ denotes the utility of alternative $j$ chosen by respondent $n$ in choice situation $s$. The 
Table 1. Attributes and levels used in discrete choice experiment.

\begin{tabular}{|c|c|c|c|c|c|c|c|}
\hline \multirow[t]{2}{*}{ Attribute } & \multirow[t]{2}{*}{ Description } & \multicolumn{6}{|c|}{ Levels } \\
\hline & & Status Quo 0 & 1 & 2 & 3 & 4 & 5 \\
\hline 1. Daily bag limit & $\begin{array}{l}\text { The number of rock lobster that } \\
\text { any licensed fisher can legally } \\
\text { retain per day }\end{array}$ & 2/day & 1/day & 3/day & & & \\
\hline 2. Season length & $\begin{array}{l}\text { The number of weeks the fishing } \\
\text { season is open }\end{array}$ & $\begin{array}{l}\text { As for } 2018 \\
\text { (24 weeks) }\end{array}$ & 16 weeks & 8 weeks & & & \\
\hline $\begin{array}{l}\text { 3. Maximum seasonal } \\
\text { catch }\end{array}$ & $\begin{array}{l}\text { Maximum number that one } \\
\text { licensed fisher can keep over the } \\
\text { entire season }\end{array}$ & No limit & 8 & 12 & 16 & 20 & 24 \\
\hline $\begin{array}{l}\text { 4. Minimum size limit } \\
\text { for females }\end{array}$ & $\begin{array}{l}\text { Minimum legal size limit for } \\
\text { female rock lobster }\end{array}$ & $\begin{array}{l}\text { As is } \\
(105 \mathrm{~mm})\end{array}$ & $\begin{array}{l}\text { Increase } \\
\text { by } 5 \mathrm{~mm}\end{array}$ & $\begin{array}{l}\text { Increase by } \\
10 \mathrm{~mm}\end{array}$ & & & \\
\hline $\begin{array}{l}\text { 5. Penalties for } \\
\text { noncompliant act }\end{array}$ & $\begin{array}{l}\text { The penalty given for } \\
\text { noncompliant acts }\end{array}$ & As is & $\begin{array}{l}\text { Increase } \\
\text { by } 50 \%\end{array}$ & & & & \\
\hline
\end{tabular}

utility $U_{n s j}$ has two separate components: (1) an observable component of the utility, $V_{n s j}$; and (2) unobservable component, $\varepsilon_{n s j}$, such that:

$$
U_{n s j}=V_{n s j}+\varepsilon_{n s j}
$$

The observable component of the utility, $V_{n s j}$, is expressed in terms of a linear combination of $k$ attributes, such that:

$$
U_{n s j}=\beta X_{n s j}+\varepsilon_{n s j}
$$

where $X_{n s j}$ is a vector of $k$ observed attributes for the good in question, and $\beta$ is a vector of the corresponding parameters (i.e., marginal utilities). In choice situation $s$, respondent $n$ will choose alternative $j$ if $U_{n s j}>U_{n s i}$ for all $j \neq i$. Assuming a Type I extreme value distribution for the unobservable component, $\varepsilon_{n s i}$, the probability that respondent $n$ chooses alternative $j$ in choice situation in $s$ is given by (Mcfadden 1981):

$$
\operatorname{Prob}\left(y_{i t}=j\right)=\frac{\exp \left(\beta X_{n s j}\right)}{\sum_{s=1}^{s} \exp \left(\beta X_{n s j}\right)}
$$

Equation (3) provides a basis to model the choices made by respondents in DCE as a function of the attributes. That is, discrete choice data are used to determine the attributes, which are significantly associated with respondents' utility, and the extent to which respondents are willing to trade one attribute for another. Although a number of challenges have been identified (Carson 2012, Hausman 2012), the usefulness of DCE to support policymaking has been widely acknowledged (Börger et al. 2014, Rogers et al. 2015, Marre et al. 2016). The main advantage of DCE over a self-reported survey is that survey respondents are placed in a choice situation requiring them to consider trade-offs between attributes and to choose the alternative that provides the greatest utility.

\section{Discrete choice experiment design}

Alternatives in a DCE are defined by a set of attributes and their levels. Table 1 provides the description of each attribute and associated levels used in this study. We based attribute and level selection on a number of sources, including: (1) a discussion paper summarizing management options to restrain rock lobster catches
(DPIPWE, unpublished data); (2) results from previous recreational rock lobster surveys (Lyle and Tracey 2016, 2017, Lyle 2018); and (3) extensive discussions with fishery experts. Because the objective of the study is to examine management preferences and the fishery is predominantly a consumptive fishery, attributes of the fishing experience were not included.

To determine the number of attributes and the levels, we first identified management tools that are already in place or have been discussed for future management use. We then selected five tools as management attribute: those considered the most effective at reducing catch in this fishery and having clear links to recreational fishing experience. The attributes included in the DCE are: (1) daily bag limit, (2) season length, (3) maximum seasonal catch limit per person, (4) minimum size limit for female rock lobster, and (5) penalties for noncompliant acts (Table 1).

The daily bag limit at the time of study was two lobster. The bag limit had been reduced from five to three in 2011 and then to two lobster per day in 2015. These reductions in bag limit appear to have had little direct impact on annual catches, in part because the higher bag limits are rarely achieved by pot fishers who account for the bulk of the total catch (Lyle et al. 2019). Therefore, we considered a further restriction to one, as well as renewing the bag limit to three as the levels of this attribute. Additionally, within a scenario in which there is an increase in bag limit, other management tools would be restricted to offset any reduction in utility, therefore total catch may not be affected. The attribute level for the season length was progressively reduced from 24 weeks (as applied in 2018) to 8 weeks. The lower limit choice has relevance because recreational fishing effort is heavily concentrated in the first two months of the season, a period that has typically accounted for over $70 \%$ of the total seasonal catch and effort (Lyle and Tracey 2016, 2017, Lyle 2018). The maximum seasonal catch limit was progressively reduced from 40 lobster, representing the upper $95^{\text {th }}$ percentile based on individual annual catches determined for previous catch and effort surveys, to 8 lobster, slightly higher than the mean individual annual catch taken by rock lobster license holders in recent years (Lyle and Tracey 2016, 2017, Lyle 2018). An increase in the minimum size limit is another restriction that has been proposed as a measure 
Fig. 2. Example choice set given to fishers.

\begin{tabular}{|c|c|c|c|}
\hline \multicolumn{4}{|l|}{ Scenario 1 (out of 6 ) } \\
\hline \multicolumn{4}{|c|}{$\begin{array}{l}\text { Please compare the following three options for the management of the Rock Lobster recreational } \\
\text { fishery in the eastern region of Tasmania. Assuming these are the only options available to you, which } \\
\text { of the options do you prefer? }\end{array}$} \\
\hline \multicolumn{4}{|c|}{$\begin{array}{l}\text { You should base your preferences considering your actual fishing experiences, for instance } \\
\text { consider these options in relation to how often you go (or would hope to go) fishing/diving for } \\
\text { lobster, your usual catch rates and the sizes of the lobsters you normally catch. }\end{array}$} \\
\hline Management feature & Option A & Option B & Option C \\
\hline Daily bag limit & $2 /$ day & $2 /$ day & I wouldn't renew my \\
\hline Season length & 8 weeks & 16 weeks & licence \\
\hline $\begin{array}{l}\text { Maximum seasonal } \\
\text { catch limit per licence } \\
\text { holder }\end{array}$ & 12 lobsters/ season & 8 lobsters/season & \\
\hline Size limit for females & Increase by $10 \mathrm{~mm}$ & As is & \\
\hline $\begin{array}{l}\text { Penalties for non- } \\
\text { compliant acts }\end{array}$ & As is & Increase by $50 \%$ & \\
\hline \multicolumn{4}{|c|}{ Ala) Which of these options do you prefer? (Please tick) } \\
\hline Option A & - Optior & & Option C \\
\hline
\end{tabular}

to assist with stock rebuilding by providing additional protection to the adult stock and enhance egg production. We set the levels of this attribute relative in scale to size increases that would provide at least a year of additional protection to breeding females. Finally, for attribute (5), we were nonspecific with the status quo level and alternative because a penalty for a noncompliant act can take many forms. All attributes, except attribute (3), are already in place in this fishery, with the status quo representing the current management. There is currently no limit on the maximum number of lobster one licensed fisher can catch in a season, however, implementing such a restriction has been discussed with resource managers and stakeholders as a potential tool to reduce the overall recreational catch.

In total, there are 324 combinations for the 5 attributes and associated levels in Table 1. It is not feasible to ask respondents to select their choice from the universe of all possible combinations. Relevant combinations of attribute levels can be generated in multiple ways, such as orthogonal designs (Louviere et al. 2000) or efficient designs (Rose and Bliemer 2009). In this study, an efficient design was used to avoid unrealistic scenarios in the management context of this fishery. Using a priori expectations of the parameter estimates, efficient designs can also improve the reliability of the estimated parameters (i.e., standard errors) for a given sample size (Huber and Zwerina 1996). The utility for each attribute was modeled using Ngene (ChoiceMetrics http://www.choice-metrics.com/index.html), which produced 18 choice sets (i.e., scenarios) with balanced utility, as per the efficient design. Although it is possible for respondents to answer all choice sets, it is common to divide the choice sets into blocks to make the DCE quicker to complete and reduce participant fatigue. We had three blocks of six choice sets. To minimize any ordering effect, we randomiszed the order of each of the blocks into five orders. The order and block of the choice sets were randomly allocated per respondent.

For each choice set, respondents were asked to compare the options and decide which option they would choose to renew their license for or whether they would choose not to renew their license (Fig. 2). Following the choice task, respondents were asked to complete a self-assessment on the understanding and confidence in completing the DCE. Respondents who opted out for every choice set were removed from the analysis because these were considered protest votes $(n=6)$, and those who answered "not certain at all" to conducting the DCE were also removed $(n=7$; Freeman 1986). In addition to the choice sets, we collected data on fishers' participation, fishing methods, demographics, and motivation and attitudes toward compliance management in the same survey.

Data analysis

Discrete choice data from the DCE were modeled by a conditional logit model that estimates the marginal utility associated with each attribute; i.e., $\beta$ in Equation (3). Estimates of the marginal 
Table 2. Fishers' opinion on effectiveness and support of management tools.

\begin{tabular}{|c|c|c|c|c|c|c|}
\hline \multirow[t]{2}{*}{ Management tool } & \multirow[b]{2}{*}{ Response } & \multicolumn{2}{|c|}{ Effective } & \multicolumn{2}{|c|}{ Support } & \multirow{2}{*}{$\begin{array}{l}\text { Support effectiveness } \\
\text { correlation }\end{array}$} \\
\hline & & No. & $\%$ & No. & $\%$ & \\
\hline \multirow[t]{3}{*}{ Reduce the daily bag limit to one per day } & Yes & 204 & 40.6 & 143 & 28.7 & 0.792 \\
\hline & No/Not really & 288 & 57.4 & 344 & 68.9 & \\
\hline & Unsure & 10 & 2.0 & 12 & 2.4 & \\
\hline \multirow{3}{*}{$\begin{array}{l}\text { Further reduce the length of the season (in } \\
\text { the eastern region) }\end{array}$} & Yes & 272 & 54.3 & 244 & 48.9 & 0.870 \\
\hline & No/Not really & 205 & 40.9 & 235 & 47.1 & \\
\hline & Unsure & 24 & 4.8 & 20 & 4.0 & \\
\hline \multirow{3}{*}{$\begin{array}{l}\text { Introduce a maximum east-coast seasonal } \\
\text { catch limit for each license holder }\end{array}$} & Yes & 380 & 75.7 & 369 & 73.9 & 0.885 \\
\hline & No/Not really & 107 & 21.3 & 114 & 22.8 & \\
\hline & Unsure & 15 & 3.0 & 16 & 3.2 & \\
\hline \multirow{3}{*}{$\begin{array}{l}\text { Increase the minimum size limit, meaning } \\
\text { more of the catch is released }\end{array}$} & Yes & 306 & 60.8 & 274 & 54.8 & 0.848 \\
\hline & No/Not really & 170 & 33.8 & 204 & 40.8 & \\
\hline & Unsure & 27 & 5.4 & 22 & 4.4 & \\
\hline \multirow{3}{*}{$\begin{array}{l}\text { Limit the number of licenses that have } \\
\text { access to the eastern region for lobster }\end{array}$} & Yes & 83 & 16.6 & 45 & 9.0 & 0.899 \\
\hline & No/Not really & 388 & 77.6 & 425 & 85.3 & \\
\hline & Unsure & 29 & 5.8 & 28 & 5.6 & \\
\hline \multirow{3}{*}{$\begin{array}{l}\text { Reduce the commercial catch allowance to } \\
\text { offset any increase in recreational catches }\end{array}$} & Yes & 291 & 58.1 & 266 & 54.6 & 0.881 \\
\hline & No/Not really & 160 & 31.9 & 175 & 35.9 & \\
\hline & Unsure & 50 & 10.0 & 46 & 9.4 & \\
\hline
\end{tabular}

utility were then used to assess if and to what extent respondents are willing to trade one management attribute for another while maintaining the same level of utility. For this, the marginal rate of substitution between two attributes provides an estimate of the relative importance of one attribute compared to the other. Specifically, we calculated the marginal rate of substitution of attributes (2)-(5), relative to reduction of bag limit by one lobster. For example, the ratio $\beta_{\text {season length }} / \beta_{\text {bag limit }}$ represents, if the bag limit was reduced by one, how long the season length would have to increase to account for the utility loss. To examine heterogeneity in preferences, we first estimated the model for the entire sample, and then for the subsample of fishers who used different methods and those who had different avidity levels. We also estimated different models to test for the sensitivity of the main results to various model specifications and assumptions (see Appendix 1).

\section{RESULTS}

Distribution of fishing methods and avidity

For fishers who participated in the phone survey, potting (either just potting or in combination with ring nets) was the most common fishing method used (51\%). Multiuse (a combination of diving and potting or ring nets) was the second largest group $(35 \%)$, and diving was the least common group $(14 \%)$. The distribution was analogous between the fishers surveyed in the phone survey and the DCE (Fig. 3a). The 50\% of fishers who participated in the DCE used only pots or pots and ring nets, $13 \%$ of fishers dived for lobster and $36 \%$ of fishers used a combination of these methods. The distribution is consistent with the distribution found in previous recreational rock lobster surveys (Lyle 2018).

The distribution of avidity of fishers (i.e., reported number of fishing days per season) differed between the phone survey and the DCE (Fig. 3b). The phone survey sample comprised of $60 \%$ low avid fishers (10 days per season or below), $29 \%$ mid avid fishers (11-25 days per season), and 11\% high avid fishers (over 25 days per season). In contrast, the DCE sample consisted of only $42 \%$ low avid fishers, $32 \%$ mid avid fishers, but $26 \%$ high avid fishers. The skew in avidity between the surveys, with high avid fishers representing more of the sample for the DCE, is likely because high avid fishers are more willing to take part in surveys related to fishing than low avid fishers. The correlation between fishing method and avidity was low for both surveys ( $r=-0.1$ for phone survey and $r=0.07$ for DCE), suggesting that heterogeneity in management preferences in the two categorizations of fishers may be different to each other.

Fig. 3. Distribution of a) fishing method by license type and b) avidity of the fishers who took part in the phone survey and the choice experiment.
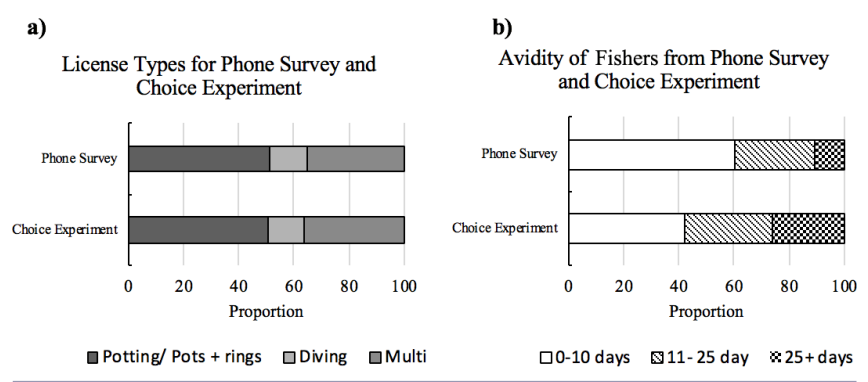

Phone survey management preferences

Support varies across the management tools. Across all the management tools, on average $45 \%$ of respondents supported the management tools, limiting license numbers was considerably 
lower at only $9 \%$ support (Table 2 ). The most strongly supported and perceived effective management tool was a maximum individual seasonal catch limit. In total $75.7 \%$ of respondents agreed that it would be an effective tool with $73.9 \%$ indicating in principle support for such a measure. However, when asked "How many lobsters would you consider as acceptable for such a seasonal catch limit?" as a follow up question, responses ranged from 2-300 lobster per fisher per season. The median was 20 lobster per season (mean 25.9), with $16 \%$ of respondents recommending limits of 40 or more and $2 \%$ limits of 100 or more lobster. The vast range in the acceptable maximum number of lobster questions the effectiveness of the management tool serving as a catch cap in practice. This would explain why limiting the number of licenses was the least supported and perceived management tool because it effectively restricts the catch in practice, i.e., $77.6 \%$ of fishers thought it was not an effective tool and $85.3 \%$ indicated they would not support it.

There is a small proportion of fishers who were unsure about the effectiveness or if they would support any of the management tools (ranging 2-10\% across different management tools). The lowest proportion of unsure responses was for a reduction in daily bag limit, suggesting high certainty of opinion, whereas $10 \%$ of fishers were unsure for a reduction of commercial catch allowance, suggesting low certainty of opinion around this management tool. There is a strong positive correlation between supporting the management tool and perceived effectiveness (last column Table 2). This suggests that if a management tool is perceived to be effective, then it is generally supported (or vice versa if it is supported then it is perceived to be effective).

We detect heterogeneity in support once we compare fishing methods and avidity levels (Fig. 4). Divers were the most supportive subgroup for all management tools, except the introduction of a seasonal catch limit. A reduction of bag limit has significantly lower support from potters and multiuse fishers than from divers $(\chi 2=15.20, \mathrm{df}=2, \mathrm{p}=0.0005)$. Likewise, an increase in size limit has more support from divers compared to potters and multiuse fishers $(\chi 2=6.75, \mathrm{df}=2, \mathrm{p}=0.034)$. There were no significant differences for the other management tools for fishing method. When categorized by avidity level, we observed that fewer avid fishers were generally more supportive of management tools. However, only a reduction of season length was significantly different for the levels of avidity $\left(\chi^{2}=7.64\right.$, df $=2, \mathrm{p}=0.02194)$.

\section{Discrete choice experiment management preferences}

The results of the choice experiment for the full responding sample showed that all management tools have positive coefficients, and this is expected because fishers on average prefer less regulation (Fig. 5). However, only a bag limit and season length were significant at the $5 \%$ level and introducing a maximum season length was significant at the $10 \%$ level. An increased minimum size limit and increased penalties were not significant for the whole sample.

When the model was estimated for the subsample of each fishing mode, bag limit had a significant coefficient for all fishing methods (Fig. 6a), meaning that there is no heterogeneity in preferences toward the bag limit. The regression, however, shows heterogeneous preferences for season length and maximum seasonal catch limit. The coefficient for season length was
Fig. 4. The proportion of fishers who support each management tool for (a) different fishing methods and (b) different levels of avidity determined by the number of fishing days per season. Unsure and NA responses were removed. Significant difference between groups from chi squared test of independence indicated by the asterisks, (p-values: $<$ $0.001=* * *,<0.01=* *,<0.05=*,<0.1=$.).

a)

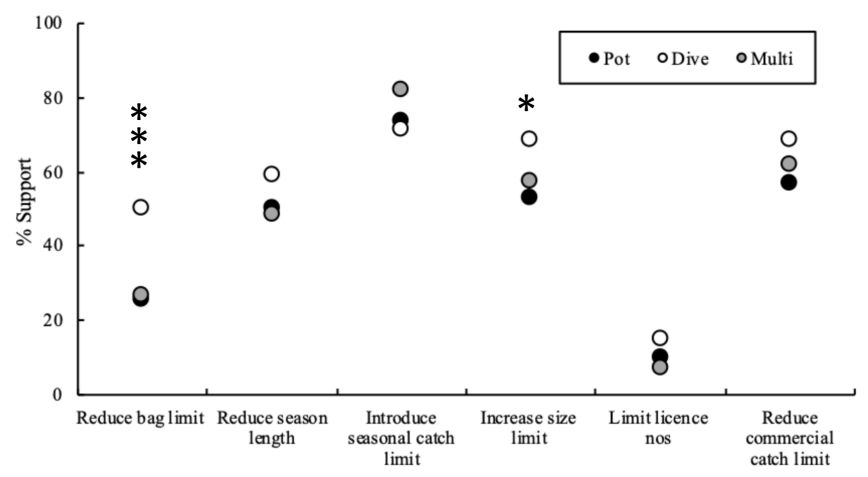

b)

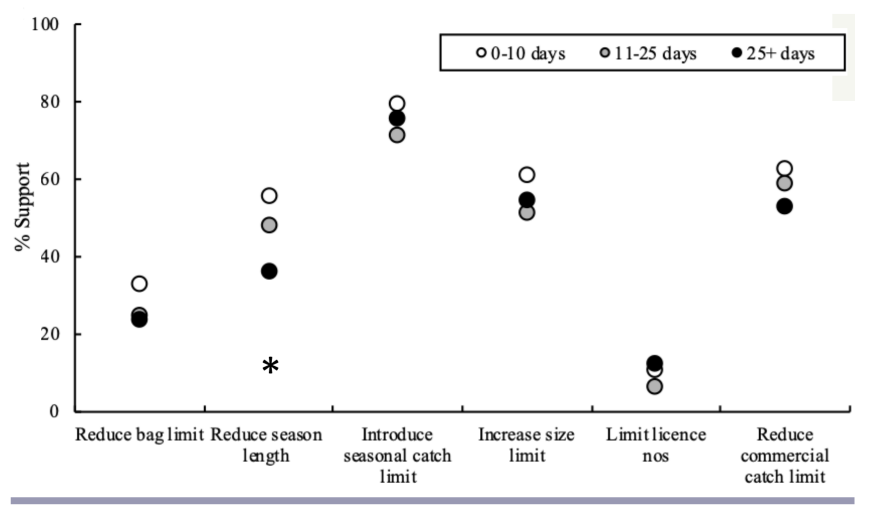

Fig. 5. Conditional logit model results of the choice experiment responses for all fishers. Error bars indicate standard error (pvalues: $<0.001=* * *,<0.01=* *,<0.05=*,<0.1=$.). See Appendix 1, Table 1 for detailed regression results.

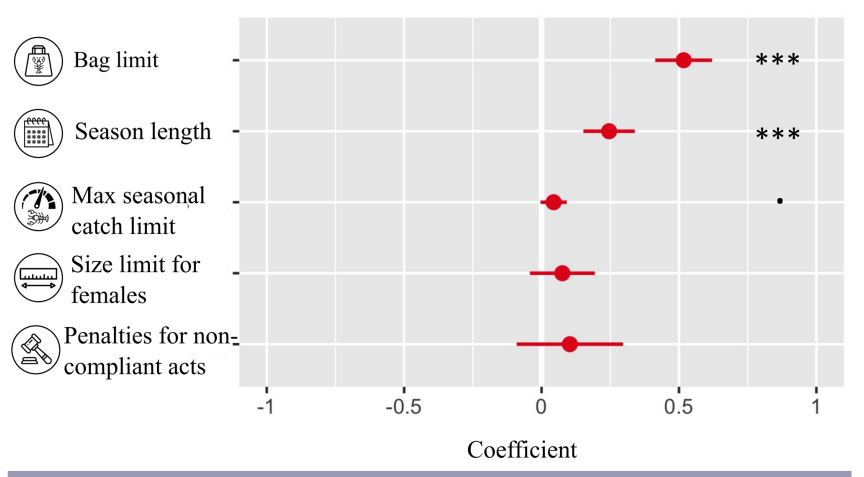


significant and positive, indicating preference for an increase in season length, for potters and multiuse fishers, but not significant for divers. This may be due to the low number of observations for this group and therefore results for this group must be interpreted with care. Likewise, the coefficient for maximum seasonal catch was significant for divers and potters only, indicating preference for a higher maximum seasonal catch (the latter only at the $10 \%$ level). All other management tools; increase in size limit and increase in penalties were not significant for all fishing methods.

Fig. 6. Conditional logit model results of the choice experiment responses for (a) each fishing method and (b) each avidity level. Error bars indicate standard error ( $\mathrm{p}$-values: $<0.001=* * *,<$ $0.01=* *,<0.05=*,<0.1=$.). See Appendix 1, Table 1 for the detailed regression results.

a)

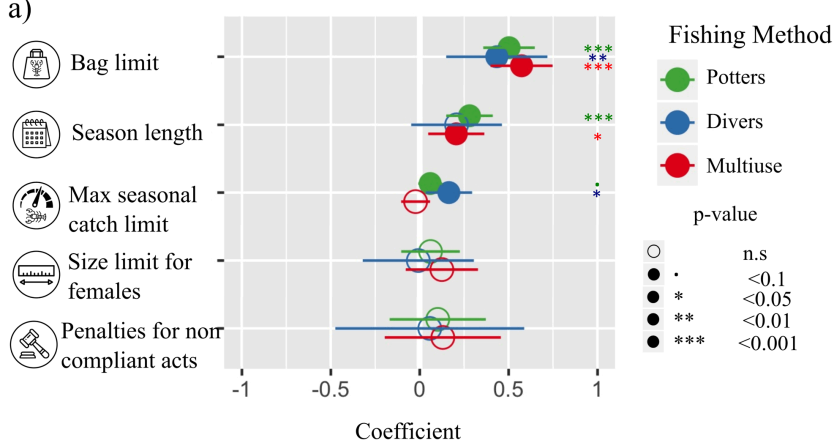

b)

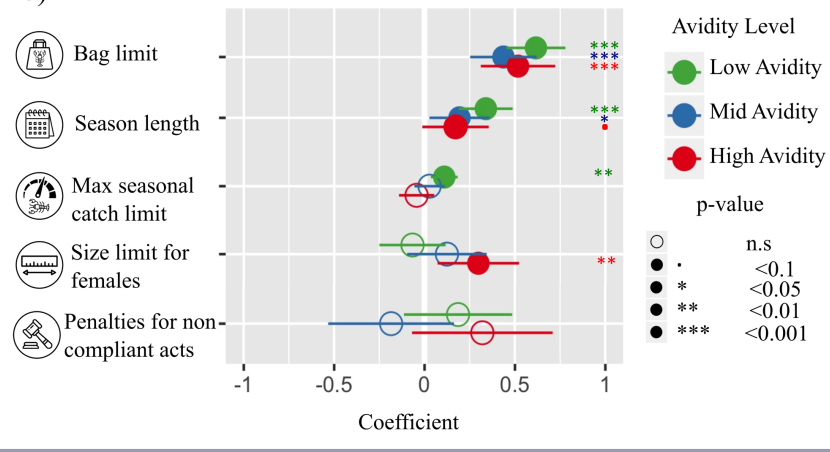

Across all levels of avidity, bag limit and an increase in season length were the management tools which have a significantly positive coefficient (Fig. 6b). A maximum seasonal catch limit was significant for low avid fishers only. An increase in size limits for females was only significant for high avid fishers whereas an increase in penalties was not significant for all fishers. A sensitivity analysis was also undertaken to statistically test differences between groups and under different model specifications (Appendix 1, Tables A1.2 and A1.3). These results show that fishers responses to the phone survey and DCE are consistent; that is, those who supported or perceived a greater number of management tools effective were more likely to be affected by management changes. We have also estimated a pooled conditional logit model, the results of which indicated that those who support the minimum size limit for females as an effective management tools are more likely to be affected by a change in this management tool.

\section{Management trade-offs}

The trade-offs fishers are willing to make for a reduction of bag limit by one lobster is reported in Figure 7 (Appendix 1, Table A1.4). The results are presented for the full sample, as well as for fishing mode and avidity level subgroups. Fishers are on average willing to accept a decrease in the bag limit by one lobster if the season length increases by 3.5 weeks (Fig. 7a). This trade-off ranges from the highest for potters ( 4.5 weeks) and low avid fishers (4.4 weeks) to the lowest for multiuse fishers ( 2.9 weeks) and high avid fishers (2.6 weeks). This result suggests that the value of season length is felt by most fishers but is relatively higher for potters and low avid fishers.

The variability across different groups of fishers in the trade-off for season length is less compared to the other management tools. The trade-off for a maximum seasonal catch is highly variable across groups (Fig. 7b). The highest trade-off is for divers at 1.5 lobsters per season, indicating that divers would be most affected by the introduction of the maximum seasonal catch limit. For size limit for females, the trade-off is highest for high avid fishers who are willing to accept a decrease in the bag limit by one lobster if the size limit for females decreases by $2.9 \mathrm{~cm}$. Finally, the tradeoff for penalties is relatively consistent across groups, except for mid and high avid fishers.

\section{DISCUSSION}

To account for behavioral responses to the management of recreational fisheries, it is important to improve our understanding of fishers' preferences toward different management tools. To this end, we conducted a phone survey and a discrete choice experiment in the rock lobster fishery in the east coast of Tasmania as a case study of a highly consumptive recreational fishery with diverse fisher groups. Acknowledging the links between avidity and fishing methods as proxies for motivations and behaviors in this fishery (Lyle 2018), we focussed on these two categorizations of fishers to evaluate recreational fishers' preferences of different management tools, which are either already in place or have been discussed for use in future management to reduce catch and assist in stock rebuilding. We specifically explored fishing mode and avidity levels because they are clear distinctions for potential intra-sector separation within this fishery with expected heterogeneity of management preferences and behaviors.

Overall our results show that preferences for some management tools are homogenous across fishers that differ in avidity and divergent fishing methods, whereas preferences for other tools are heterogenous. There was consensual aversion toward a reduction in daily bag limit. This was evident from the low perceived effectiveness and support, and the finding that a reduction in daily bag limit significantly decreases fishers' utility for all groups. This was anticipated because it is a highly consumptive harvestoriented fishery and a high value is given to immediate gratification. A reduction in season length was another management tool that was found to have an impact on most fishers' utility, except divers and high avid fishers. In the phone survey, however, highly avid fishers indicated the lowest support for a reduction in season length and the trade-off between season length and daily bag limit had little variability across groups indicating a homogenous preference toward season length. In contrast to these management tools, we found heterogeneous 
Fig. 7. Trade-offs fishers are willing to make between a reduction in bag limit by one lobster and a change in (a) season length, (b) maximum seasonal catch, (c) minimum size limit for females, and (d) penalties for noncompliant acts. See Appendix 1, Table 4 for detailed results.
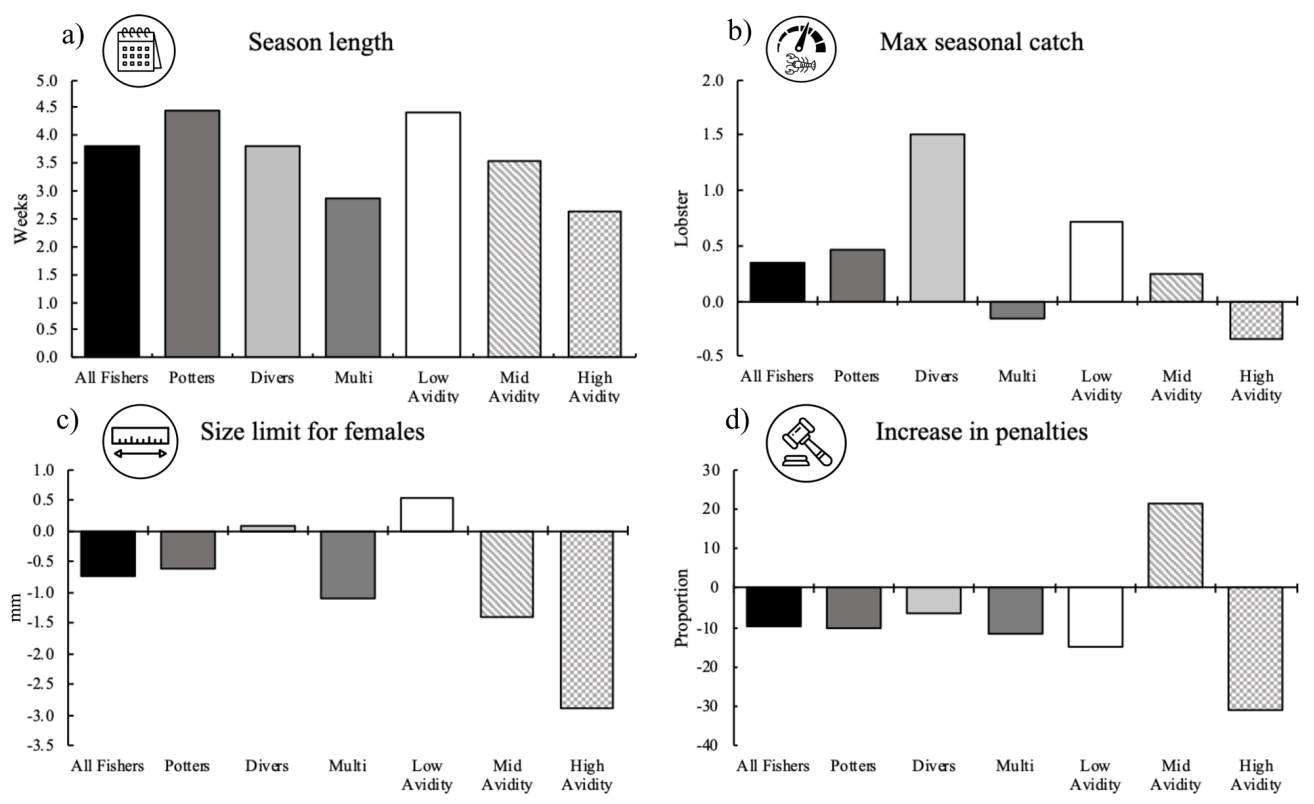

preferences for an introduced maximum seasonal catch and an increase in minimum size limit. These results may reflect the fact that the management tools in which there was heterogeneity in preferences limit catch indirectly. A reduction in bag limit and a shortened season, however, have direct and clear implications on expected catch and recreation time. There was clear consensus among fishers about these management tools, whereas a change in size limit or an introduced maximum seasonal catch require some individual reflection on their historical and expected catch rates and sizes.

Among fishers who use different fishing methods, the phone survey results suggested that divers were generally the most supportive group for further management. However, the DCE showed that these fishers would be the most impacted if a maximum seasonal catch was implemented. This was indicated by the largest trade-off required in the maximum seasonal catch. This is expected because divers had the largest average daily harvest rates in 2017/2018 compared to the other fishing methods (average 1.59 lobster per day fished for dive collection compared to 1.38 for rings and 0.73 for pots; Lyle 2018). However, our results also suggest that most fishers will be affected if a maximum seasonal catch limit is implemented to meet the stock rebuilding goals. Given the number of recreational fishers in the 2017/2018 season, the maximum season catch would need to be set at $\sim 4$ lobster per fisher to meet the 42-tonne total allowable recreational catch for the east coast region of Tasmania. This is considerably lower than the mean or median acceptable number of lobsters per season (25.9 and 20, respectively) perceived by fishers. This assumes that every fisher would catch their limit; in reality this limit would have the most impact on the high avid fishers and a lot of fishers would actually catch this limit or under.

\section{SPECULATIONS}

The results suggest there is potential for intra-sector separation management within this highly consumptive multiuse fishery. For example, although high avid fishers only accounted for a small proportion of our survey, they accounted for the most impact on stocks because they fish most frequently. Our survey results found low avid fishers were generally most supportive for all management tools in the phone survey, except limiting the number of licenses, whereas high avid fishers had the lowest support for most management tools. It is crucial for the high avid population to be compliant with the regulatory settings to support long-term sustainability of the rock lobster population. In this case, fisheries managers could implement regulations that have the greatest impact on this group (Doerpinghaus et al. 2014). For example, for high avid fishers, an increase in penalties was not significant in the DCE, however, there was a large marginal rate of substitution for penalties compared to a reduction in bag limit. Therefore, the use of economic incentives or disincentives targeting this subgroup may be highly effective; for example, a higher license fee for those fishing more than 25 days a season. Alternatively, management measures and settings can be tailored by fishing method based on preferences and behaviors. On average, potters fish more regularly per season but have lower catch rates (Lyle 2018), therefore efforts to reduce catch could be tailored around season length. Divers, on the other hand, spend on average half as many days harvesting per season but have higher catch rates (Lyle 2018), therefore tailored regulatory settings could reduce daily or seasonal catch limits. The implementation of any new regulatory settings especially subgroup specific would have to be carefully done to minimize unintended consequences or noncompliance. However, the diverse preferences and behaviors of these subgroups could be 
accounted for through tailored regulatory settings that can maximize catch and utility. The nuance between fisher groups was more evident in the discrete choice experiment compared to the phone survey. Given this finding, it would appear that in a context with prominent intra-sector separation, a discrete choice experiment is a more valuable tool compared to a survey alone for measuring heterogeneous fisher utility.

There are some caveats that should be considered when our results are interpreted and applied to other recreational fisheries. Despite efforts to reduce sampling biases like random selection, there is a chance the sample may be a product of participation/nonresponse bias because the respondents who refused to take part may have varied with the reported results; there is a chance of self-selection bias in the fishers who chose to take part in both surveys, which will affect generalizability of the results; and there may have been strategic bias in the phone survey in which fishers were asked to express their opinions about each management tool independently. Although the survey was conducted with no reference to government involvement, fishers may have not revealed true beliefs because of the sensitivity of the topic. For example, fishers may have indicated that a tool was not effective or not having support because they would not want this tool to be implemented; e.g., low support and perceived effectiveness for bag limit reduction. The joint use of an opinion-based measure of management preferences and DCE analysis may help to identity such potential bias because DCEs force survey participants to consider trade-offs between different management tools. There was a skewed representation of high avid fishers in the DCE data. This is consistent with other literature, in which a self-nominated survey represents a subpopulation of more avid fishers (Mcllgorm et al. 2016). Although our results from the phone survey and DCE are consistent with each other, the more significant preference heterogeneity across different avidity levels identified in the DCE analysis is possibly due to the higher representation of high avid fishers in the data. Lastly, we categorized fishers prior to the data analysis using fishing methods and avidity because they are indicative of fishers' motivations and behavior in our case study (Lyle 2018). However, in fisheries in which these relationships are not well established, a subgroup categorization of fishers is not possible, other potential grouping to explore underlying heterogeneity would be age and resident/nonresident. An alternative way to deal with potential heterogeneity in preferences is to use a latent class model. Although the details of these models are provided in Hensher et al. (2005), the models assume that individual preferences for each attribute are not fixed within the sample but can be categorized into group preferences (latent class models).

\section{CONCLUSION}

We set out to understand the heterogeneity in fishers' preferences across different fishing methods and avidity levels. We found that there is some consensus in opinions and preferences for management tools, and this was related to how direct a management tool has on catch. The importance, application, and novelty of these results relate to the added insight toward effective evidence-based decision making for recreational fisheries management. Within this context, for example, it was highlighted that a reduction in bag limit or season length would be disruptive to all fishers, which may even lead fishers to leave the fishery or to practice noncompliant behavior. Changes to the management tools that had less consistency in preference, such as an increase in minimum size limit, may be better received and have less impact on fishers' behavior because they do have an impact on catch but indirectly. Considering the multiple objectives that are involved in fisheries management, the results provide the necessary understanding of preferences across the groups and for each management tool. Management tools that target indirect catch reduction may be a more successful tactic to fulfil restocking goals while minimizing utility impact of fishers. Using an approach to evaluate preferences for inclusion in the decision-making process is highly advisable because decision makers can justify decisions on accordant divergent preferences and weigh up the trade-offs in different management tools. We expect future research to build on this understanding that fisheries may have homogenous and heterogeneous preferences and behaviors to then better assess and explain actions in catch, compliance, and participation that may have previously been amalgamated and generalized across the fishing population.

\section{Responses to this article can be read online at: http://www.ecologyandsociety.org/issues/responses. php/11602}

\section{Acknowledgments:}

We thank the recreational fishers for taking part in the phone and discrete choice experiment survey and Fiona Ewing for data management and logistics. Funding for this study was provided by the Australian Government through the Fisheries Research and Development Corporation and the Institute for Marine and Antarctic Studies, University of Tasmania. All data collection was carried out following the guidelines and with the approval of UTAS Human Research Ethics Committee (H0017285).

\section{Data Availability Statement:}

The datalcode that support the findings of this study are available on request from the corresponding author MM. The datalcode are not publicly available because they contain information that could compromise the privacy of research participants.

\section{LITERATURE CITED}

Aas, Ø., W. Haider, and L. Hunt. 2000. Angler responses to potential harvest regulations in a Norwegian sport fishery: a conjoint-based choice modeling approach. North American Journal of Fisheries Management 20(4):940-950. https://doi. org/10.1577/1548-8675(2000)020<0940:ARTPHR>2.0.CO:2

Aas, Ø., and J. Skurdal. 1996. Fishing by residents and nonresidents in a rural district in Norway: subsistence and sport conflict or coexistence? Nordic Journal of Freshwater Research 72:45-51.

Adamowicz, W., J. Louviere, and J. Swait. 1998. Introduction to attribute-based stated choice methods. Alternatives 105 (January):1339-1342.

Agnew, D. J., J. Pearce, G. Pramod, T. Peatman, R. Watson, J. R. Beddington, and T. J. Pitcher. 2009. Estimating the worldwide 
extent of illegal fishing. PLoS ONE 4(2):e4570. https://doi. org/10.1371/journal.pone.0004570

Arlinghaus, R., and T. Mehner. 2004. A management-orientated comparative analysis of urban and rural anglers living in a metropolis (Berlin, Germany). Environmental Management 33 (3):331-344. https://doi.org/10.1007/s00267-004-0025-X

Beardmore, B., W. Haider, L. M. Hunt, and R. Arlinghaus. 2013. Evaluating the ability of specialization indicators to explain fishing preferences. Leisure Sciences 35(3):273-292. https://doi. org/10.1080/01490400.2013.780539

Bess, R., and R. Rallapudi. 2007. Spatial conflicts in New Zealand fisheries: the rights of fishers and protection of the marine environment. Marine Policy 31(6):719-729. https://doi.org/10.1016/ j.marpol.2006.12.009

Börger, T., N. J. Beaumont, L. Pendleton, K. J. Boyle, P. Cooper, S. Fletcher, T. Haab, M. Hanemann, T. L. Hooper, S. S. Hussain, R. Portela, M. Stithou, J. Stockill, T. Taylor, and M. C. Austen. 2014. Incorporating ecosystem services in marine planning: the role of valuation. Marine Policy 46:161-170. https://doi. org/10.1016/j.marpo1.2014.01.019

Carson, R. T. 2012. Contingent valuation: a practical alternative when prices aren't available. Journal of Economic Perspectives 26 (4):27-42. https://doi.org/10.1257/jep.26.4.27

Cooke, S. J., W. M. Twardek, A. J. Reid, R. J. Lennox, S. C. Danylchuk, J. W. Brownscombe, S. D. Bower, R. Arlinghaus, K. Hyder, and A. J. Danylchuk. 2019. Searching for responsible and sustainable recreational fisheries in the Anthropocene. Journal of Fish Biology 94(6):845-856. https://doi.org/10.1111/jfb.13935

Department of Primary Industries, Parks, Water and Environment (DPIPWE). 2018. Tasmanian rock lobster fishery east coast stock rebuilding strategy 2013-2023. Wild Fisheries Management Branch, Department of Primary Industries, Parks, Water and Environment, Hobart, Tasmania, Australia. [online] URL: https://dpipwe.tas.gov.au/Documents/East Coast StockRebuilding Strategy Sept18.pdf

Ditton, R. B., and S. G Sutton. 2004. Substitutability in recreational fishing. Human Dimensions of Wildlife 9(2):87-102. https://doi.org/10.1080/10871200490441748

Doerpinghaus, J., K. Hentrich, M. Troup, A. Stavrinaky, and S. Anderson. 2014. An assessment of sector separation on the Gulf of Mexico recreational red snapper fishery. Marine Policy 50:309-317. https://doi.org/10.1016/j.marpol.2014.06.007

Duttweiler, M. W. 1976. Use of questionnaire surveys in forming fishery management policy. Transactions of the American Fisheries Society 105(2):232-239. https://doi.org/10.1577/1548-8659 (1976)105<232:UOQSIF>2.0.CO:2

Fedler, A. J., and R. B. Ditton. 1994. Understanding angler motivations in fisheries management. Fisheries 19(4):6-13. https:// doi.org/10.1577/1548-8446(1994)019<0006:UAMIFM>2.0.CO:2

Freeman, A. 1986. On assessing the state of the art of the contingent valuation method of valuing environmental changes. In R. G. Cummings, D. S. Brookshire, and W. D. Schulze, editors. Valuing environmental goods: an assessment of the contingent valuation method. Rowman and Allanheld, Totwa, New Jersey, USA.
Frijlink, S., and J. M. Lyle. 2010. An evaluation of motivations, attitudes and awareness of Tasmanian recreational fishers. Tasmanian Aquaculture and Fisheries Institute, Hobart, Tasmania, Australia. [online] URL: http://dpipwe.tas.gov.au/ Documents/Motivation-Attitude Report.pdf

Fulton, E. A., A. Smith, D. Smith, and I. E. van Putten. 2011. Human behaviour: the key source of uncertainty in fisheries management. Fish and Fisheries 12(1):2-17. https://doi. org/10.1111/j.1467-2979.2010.00371.x

Han, J. H., and C.-O. Oh. 2018. The causal mechanisms of environmentally responsible behaviors using value orientations and recreation specialization. Leisure Sciences 10:1-23. https:// doi.org/10.1080/01490400.2018.1491352

Hausman, J. 2012. Contingent valuation: from dubious to hopeless. Journal of Economic Perspectives 26(4):43-56. https:// doi.org/10.1257/jep.26.4.43

Hensher, D. A., J. M. Rose, and W. H. Greene. 2005. Applied choice analysis: a primer. Cambridge University Press, Cambridge, UK. https://doi.org/10.1017/CBO9780511610356

Hobday, A. J., A. D. M. Smith, I. C. Stobutzki, C. Bulman, R. Daley, J. M. Dambacher, R. A. Deng, J. Dowdney, M. Fuller, D. Furlani, S. P. Griffiths, D. Johnson, R. Kenyon, I. A. Knuckey, S. D. Ling, R. Pitcher, K. J. Sainsbury, M. Sporcic, T. Smith, C. Turnbull, T. I. Walker, S. E. Wayte, H. Webb, A. Williams, B. S. Wise, and S. Zhoub. 2011. Ecological risk assessment for the effects of fishing. Fisheries Research 108(2-3):372-384. https://doi. org/10.1016/j.fishres.2011.01.013

Hofmann, E. E., and T. M. Powell. 1998. Environmental variability effects on marine fisheries: four case histories. Ecological Applications 8:S23-S32. https://doi.org/10.1890/1051-0761 (1998)8[s23:eveomf]2.0.co;2

Hoshino, E., E. I. van Putten, W. Girsang, B. P. Resosudarmo, and S. Yamazaki. 2017. Fishers' perceived objectives of community-based coastal resource management in the Kei Islands, Indonesia. Frontiers in Marine Science 4(May):1-11. https://doi.org/10.3389/fmars.2017.00141

Huber, J., and K. Zwerina. 1996. The importance of utility balance in efficient choice designs. Journal of Marketing Research 33:307-317. https://doi.org/10.2307/3152127

Lancaster, K. J. 1966. A new approach to consumer theory. Journal of Political Economy 74(2):132-157.

Louviere, J. J., D. A. Hensher, and J. D. Swait. 2000. Stated choice methods: analysis and applications. Cambridge University Press, Cambridge, UK. https://doi.org/10.1017/CBO9780511753831

Lyle, J. M. 2018. Tasmanian recreational rock lobster and abalone fisheries: 2017-18 fishing season. Institute for Marine and Antarctic Studies, University of Tasmania, Hobart, Tasmania, Australia. [online] URL: https://imas.utas.edu.au/ data/assets/ pdf file/0004/1158718/1718 RLAB FWMG FINAL.pdf

Lyle, J. M., F. Ewing, G. Ewing, and S. R. Tracey. 2019. Tasmanian recreational rock lobster and abalone fisheries: 2018-19 fishing season. Institute for Marine and Antarctic Studies, University of Tasmania, Hobart, Tasmania, Australia. [online] URL: https:// dpipwe.tas.gov.au/Documents/Rock_Lobster_Abalone_Survey_18-19. pdf 
Lyle, J. M., and S. R. Tracey. 2016. Tasmanian recreational rock lobster and abalone fisheries 2014-2015 season. Institute of Antarctic and Marine Studies, University of Tasmania, Hobart, Tasmania, Australia. [online] URL: https://tasabalone.com.au/ wp-content/uploads/2014/03/20161025-14-15 RLAB_FWMG_FINAL-1. pdf

Lyle, J. M., and S. R. Tracey. 2017. Tasmanian recreational rock lobster and abalone fisheries: 2016-17 fishing season. Institute for Marine and Antarctic Studies, University of Tasmania, Hobart, Tasmania, Australia.

Marre, J.-B., O. Thébaud, S. Pascoe, S. Jennings, J. Boncoeur, and L. Coglan. 2016. Is economic valuation of ecosystem services useful to decision-makers? Lessons learned from Australian coastal and marine management. Journal of Environmental Management 178:52-62. https://doi.org/10.1016/j.jenvman.2016.04.014

Matlock, G. C., G. E. Saul, and C. E. Bryan. 1988. Importance of fish consumption to sport fishermen. Fisheries 13(1):25-26. https://doi.org/10.1577/1548-8446(1988)013<0025:IOFCTS >2.0. $\underline{\mathrm{CO} ; 2}$

Matsumura, S., B. Beardmore, W. Haider, U. Dieckmann, and R. Arlinghaus. 2019. Ecological, angler, and spatial heterogeneity drive social and ecological outcomes in an integrated landscape model of freshwater recreational fisheries. Reviews in Fisheries Science and Aquaculture 27:170-197. https://doi.org/10.1080/23$\underline{308249.2018 .1540549}$

Mcfadden, D. 1981. Econometric models of probabilistic choice. Pages 198-269 in C. F. Manski and D. McFadden, editors. Structural analysis of discrete data with econometric applications. MIT Press, Cambridge, Massachusetts, USA.

Mcllgorm, A., M. A. Voyer, C. Magee, J. Pepperell, E. O’toole, and $\mathrm{O}$. Li. 2016. Improving our understanding of the motivations and attitudes of recreational fishers in NSW. New South Wales Department of Primary Industry Recreational Fishing Trusts, Orange, New South Whales, Australia. [online] URL: https:// documents.uow.edu.au/content/groups/public/@web/@1aw/@ancors/ documents/doc/uow224967.pdf

Renyard, T. S., and R. Hilborn. 1986. Sports angler preferences for alternative regulatory methods. Canadian Journal of Fisheries and Aquatic Sciences 43(1):240-242. https://doi.org/10.1139/ $\underline{\text { f86-029 }}$

Rogers, A. A., M. E. Kragt, F. L. Gibson, M. P. Burton, E. H. Petersen, and D. J. Pannell. 2015. Non-market valuation: usage and impacts in environmental policy and management in Australia. Australian Journal of Agricultural and Resource Economics 59(1):1-15. https://doi.org/10.1111/1467-8489.12031

Rose, J. M., and M. C. J. Bliemer. 2009. Constructing efficient stated choice experimental designs. Transport Reviews 29 (5):587-617. https://doi.org/10.1080/01441640902827623

Scott, D., and C. S. Shafer. 2001. Recreational specialization: a critical look at the construct. Journal of Leisure Research 33 (3):319-343. https://doi.org/10.1080/00222216.2001.11949944

Stoop, J., C. N. Noussair, and D. van Soest. 2012. From the lab to the field: cooperation among fishermen. Journal of Political Economy 120(6):1027-1056. https://doi.org/10.1086/669253
Teisl, M. F., K. J. Boyle, and O. C. Fenderson. 1993. Angler opinions regarding management options to balance open-water and ice fishing effort in Maine. North American Journal of Fisheries Management 13(2):353-359. https://doi.org/10.1577/1548-8675 (1993) $013<0353:$ AORMOT>2.3.CO;2

Tsangarides, C. 2007. A social critique of the failings of management in the North Sea ecosystem: subterranean North Sea blues. Thesis. Natural Resource Management Governance and Globalisation, Centre for Transdisciplinary Environmental Research, Stockholm University, Stockholm, Sweden. [online] URL: https://www.stockholmresilience.org/download/18. aeea46911a31274279800082934/Tsangarides+NGG+07+Thesis. pdf

van Putten, I. E., S. Jennings, A. J. Hobday, R. H. Bustamante, L. X. C. Dutra, S. Frusher, E. A. Fulton, M. Haward, E. Plagányi, L. Thomas, and G. Pecl. 2017. Recreational fishing in a time of rapid ocean change. Marine Policy 76:169-177. https://doi. org/10.1016/j.marpol.2016.11.034

Yamazaki, S., S. Rust, S. Jennings, J. Lyle, and S. Frijlink. 2011. A contingent valuation of recreational fishing in Tasmania. Institute of Antarctic and Marine Studies, University of Tasmania, Hobart, Tasmania, Australia. [online] URL: http://www.imas. utas.edu.au/ data/assets/pdf file/0003/743250/FISHWISE -CVsurvey-of-Tas Recfishery report.pdf 
Appendix 1. Model results and sensitivity analysis

Table A.1. Conditional logit on discrete choice experiment data for different fishing methods and fishing avidity levels

\begin{tabular}{|c|c|c|c|c|c|c|c|}
\hline & \multirow{2}{*}{$\begin{array}{c}\text { Figure } 5 \\
\text { All fishers } \\
\end{array}$} & \multicolumn{3}{|c|}{ Figure 6 (a) } & \multicolumn{3}{|c|}{ Figure 6 (b) } \\
\hline & & Potters & Divers & Multi & Low avidity & Mid avidity & High avidity \\
\hline \multirow{2}{*}{ Bag limit } & 0.517 & 0.502 & 0.433 & 0.573 & 0.616 & 0.437 & 0.517 \\
\hline & $(<0.001)^{* * *}$ & $(<0.001)^{* * *}$ & $(0.003)^{* *}$ & $(<0.001) * * *$ & $(<0.001)^{* * *}$ & $(<0.001)^{* * *}$ & $(<0.001)^{* * *}$ \\
\hline \multirow{2}{*}{ Season length } & 0.246 & 0.28 & 0.207 & 0.205 & 0.339 & 0.193 & 0.171 \\
\hline & $(<0.001)^{* * *}$ & $(<0.001)^{* * *}$ & $(0.111)$ & $(0.011)^{*}$ & $(<0.001)^{* * *}$ & $(0.023)^{*}$ & $(0.068)^{\wedge}$ \\
\hline \multirow{2}{*}{ Maximum seasonal catch limit } & 0.044 & 0.059 & 0.164 & -0.023 & 0.109 & 0.027 & -0.044 \\
\hline & $(0.072)^{\wedge}$ & $(0.085)^{\wedge}$ & $(0.014)^{*}$ & $(0.574)$ & $(0.004)^{* *}$ & $(0.523)$ & $(0.374)$ \\
\hline \multirow{2}{*}{ Size limit } & 0.076 & 0.061 & -0.008 & 0.125 & -0.067 & 0.124 & 0.298 \\
\hline & $(0.209)$ & $(0.468)$ & $(0.961)$ & $(0.229)$ & $(0.475)$ & $(0.270)$ & $(0.010)^{* *}$ \\
\hline \multirow{2}{*}{ Penalties for non-compliant acts } & 0.103 & 0.102 & 0.057 & 0.131 & 0.186 & -0.184 & 0.32 \\
\hline & $(0.297)$ & $(0.460)$ & $(0.833)$ & $(0.433)$ & $(0.223)$ & $(0.299)$ & $(0.106)$ \\
\hline \multirow{2}{*}{ Constant } & -1.979 & -2.041 & -2.045 & -1.864 & -2.395 & -1.657 & -1.877 \\
\hline & $(<0.001)^{* * *}$ & $(<0.001)^{* * *}$ & $(<0.001)^{* * *}$ & $(<0.001)^{* * *}$ & $(<0.001)^{* * *}$ & $(<0.001)^{* * *}$ & $(<0.001)^{* * *}$ \\
\hline Number of observations & 2,574 & 1,314 & 342 & 918 & 1,080 & 828 & 666 \\
\hline Number of subjects & 143 & 72 & 19 & 51 & 60 & 46 & 37 \\
\hline Log-likelihood & -1459.7 & -740.7 & -193.7 & -521.7 & -582.5 & -486.7 & -377.7 \\
\hline McFadden's pseudo-R2 & 0.109 & 0.114 & 0.11 & 0.107 & 0.153 & 0.077 & 0.109 \\
\hline AIC & 2931.3 & 1493.5 & 399.39 & 1055.4 & 1176.9 & 985.34 & 767.43 \\
\hline
\end{tabular}


Table A.2. Sensitivity analysis: different model specifications

\begin{tabular}{|c|c|c|c|c|c|c|c|}
\hline & \multirow{2}{*}{$\begin{array}{c}\text { Baseline } \\
\text { (Figure 5) }\end{array}$} & \multirow[b]{2}{*}{ Mixed logit } & \multicolumn{5}{|c|}{ Subsample } \\
\hline & & & Non-potters & Support & Non-support & Effective & Non-effective \\
\hline \multirow{2}{*}{ Bag limit } & 0.517 & 0.657 & 0.533 & 0.495 & 0.472 & 0.450 & 0.618 \\
\hline & $(<0.001)^{* * *}$ & $(<0.001)^{* * *}$ & $(<0.001)^{* * *}$ & $(<0.001)^{* * *}$ & $(<0.001)^{* * *}$ & $(<0.001)^{* * *}$ & $(<0.001)^{* * *}$ \\
\hline \multirow{2}{*}{ Season length } & 0.246 & 0.230 & 0.210 & 0.519 & 0.223 & 0.438 & 0.211 \\
\hline & $(<0.001)^{* * *}$ & $(0.013)^{*}$ & $(0.002)^{* *}$ & $(<0.001)^{* * *}$ & $(0.003)^{* *}$ & $(<0.001)^{* * *}$ & $(0.007)^{* *}$ \\
\hline \multirow{2}{*}{ Maximum seasonal catch limit } & 0.044 & -0.007 & 0.028 & 0.179 & 0.016 & 0.052 & -0.008 \\
\hline & $(0.072)^{\wedge}$ & $(0.918)$ & $(0.416)$ & $(<0.001)^{* * *}$ & $(0.688)$ & $(0.180)$ & $(0.834)$ \\
\hline \multirow{2}{*}{ Size limit } & 0.076 & 0.089 & 0.091 & 0.091 & -0.141 & 0.208 & -0.233 \\
\hline & $(0.209)$ & $(0.347)$ & $(0.290)$ & $(0.440)$ & $(0.140)$ & $(0.026)^{*}$ & $(0.021)^{*}$ \\
\hline \multirow{2}{*}{ Penalties for non-compliant acts } & 0.103 & 0.135 & 0.106 & 0.012 & 0.065 & -0.010 & 0.192 \\
\hline & $(0.297)$ & $(0.431)$ & $(0.452)$ & $(0.951)$ & $(0.683)$ & $(0.948)$ & $(0.234)$ \\
\hline \multirow{2}{*}{ Constant } & -1.979 & -2.133 & -1.917 & -2.788 & -1.608 & -2.277 & -1.723 \\
\hline & $(<0.001)^{* * *}$ & $(<0.001)^{* * *}$ & $(<0.001)^{* * *}$ & $(<0.001)^{* * *}$ & $(<0.001)^{* * *}$ & $(<0.001)^{* * *}$ & $(<0.001)^{* * *}$ \\
\hline Number of observations & 2,574 & 2,574 & 1260 & 702 & 1,008 & 1044 & 990 \\
\hline Number of subjects & 143 & 143 & 70 & 39 & 56 & 58 & 55 \\
\hline Log-likelihood & -1459.7 & -1457.0 & -718.4 & -361.1 & -597.3 & -569.5 & -570.8 \\
\hline McFadden's pseudo-R2 & 0.109 & 0.104 & 0.104 & 0.192 & 0.069 & 0.143 & 0.094 \\
\hline AIC & 2931.3 & 2938.0 & 1448.8 & 734.19 & 1206.6 & 1151.0 & 1153.6 \\
\hline
\end{tabular}

Note: This table reports the estimates of the coefficients and $p$-values in parentheses from different model specifications. $p$-values: $<0.001=* * *$, $<0.01=* *,<0.05=*,<0.1=\wedge$. Non-potters correspond to the subsample of divers and multi-use fishers; Support correspond to the subsample of fishers who are supportive to more than three management tools in the phone survey; Non-support correspond to the subsample of fishers who are supportive to less than three management tools; Effective corresponds to the subsample of fishers who perceive more than three management tools effective; and non-effective corresponds to the sub-sample of fishes who perceive less than three management tools effective. 
Table A.3. Sensitivity analysis: conditional logit model with interaction terms

\begin{tabular}{|c|c|c|c|c|c|}
\hline & $\begin{array}{c}\text { Baseline } \\
\text { (Figure 5) }\end{array}$ & Method & Avidity & Support & Effective \\
\hline Bag limit & $\begin{array}{c}0.517 \\
(<0.001)^{* * *}\end{array}$ & $\begin{array}{c}0.532 \\
(<0.001)^{* * *}\end{array}$ & $\begin{array}{c}0.514 \\
(<0.001) * * *\end{array}$ & $\begin{array}{c}0.523 \\
(<0.001)^{* * *}\end{array}$ & $\begin{array}{c}0.550 \\
(<0.001)^{* * *}\end{array}$ \\
\hline Season length & $\begin{array}{c}0.246 \\
(<0.001)^{* * *}\end{array}$ & $\begin{array}{c}0.252 \\
(<0.001)^{* * *}\end{array}$ & $\begin{array}{c}0.270 \\
(<0.001)^{* * *}\end{array}$ & $\begin{array}{c}0.205 \\
(<0.001)^{* * *}\end{array}$ & $\begin{array}{c}0.199 \\
(<0.001)^{* * *}\end{array}$ \\
\hline $\begin{array}{l}\text { Maximum seasonal catch } \\
\text { limit }\end{array}$ & $\begin{array}{c}0.044 \\
(0.072)^{\wedge}\end{array}$ & $\begin{array}{c}0.026 \\
(0.315)\end{array}$ & $\begin{array}{c}0.069 \\
(0.013) *\end{array}$ & $\begin{array}{c}0.044 \\
(0.204)\end{array}$ & $\begin{array}{c}0.045 \\
(0.198)\end{array}$ \\
\hline Size limit for females & $\begin{array}{c}0.076 \\
(0.209)\end{array}$ & $\begin{array}{c}0.087 \\
(0.181)\end{array}$ & $\begin{array}{l}-0.004 \\
(0.958)\end{array}$ & $\begin{array}{l}-0.137 \\
(0.087)^{\wedge}\end{array}$ & $\begin{array}{c}-0.207 \\
(0.014) *\end{array}$ \\
\hline $\begin{array}{l}\text { Penalties for non-compliant } \\
\text { acts }\end{array}$ & $\begin{array}{c}0.103 \\
(0.297)\end{array}$ & $\begin{array}{c}0.112 \\
(0.292)\end{array}$ & $\begin{array}{c}0.032 \\
(0.780)\end{array}$ & $\begin{array}{c}0.054 \\
(0.600)\end{array}$ & $\begin{array}{c}0.069 \\
(0.498)\end{array}$ \\
\hline \multicolumn{6}{|l|}{$\begin{array}{l}\text { Divers, High avid, Support or } \\
\text { Effective }\end{array}$} \\
\hline$\times$ Bag limit & & $\begin{array}{l}-0.111 \\
(0.451)\end{array}$ & $\begin{array}{c}0.023 \\
(0.844)\end{array}$ & $\begin{array}{c}0.009 \\
(0.870)\end{array}$ & $\begin{array}{l}-0.062 \\
(0.248)\end{array}$ \\
\hline$\times$ Season length & & $\begin{array}{l}-0.056 \\
(0.672)\end{array}$ & $\begin{array}{l}-0.082 \\
(0.427)\end{array}$ & $\begin{array}{c}0.069 \\
(0.164)\end{array}$ & $\begin{array}{c}0.070 \\
(0.176)\end{array}$ \\
\hline$\times$ Maximum seasonal catch & & $\begin{array}{c}0.133 \\
(0.052)^{\wedge}\end{array}$ & $\begin{array}{l}-0.106 \\
(0.053)^{\wedge}\end{array}$ & $\begin{array}{l}-0.012 \\
(0.696)\end{array}$ & $\begin{array}{l}-0.003 \\
(0.931)\end{array}$ \\
\hline$\times$ Size limit for females & & $\begin{array}{l}-0.098 \\
(0.569)\end{array}$ & $\begin{array}{c}0.307 \\
(0.023) *\end{array}$ & $\begin{array}{c}0.371 \\
(<0.001)^{* * *}\end{array}$ & $\begin{array}{c}0.436 \\
(<0.001)^{* * *}\end{array}$ \\
\hline$\times$ Penalties & & $\begin{array}{l}-0.057 \\
(0.843)\end{array}$ & $\begin{array}{c}0.293 \\
(0.200)\end{array}$ & & \\
\hline Constant & $\begin{array}{c}-1.979 \\
(<0.001)^{* * *}\end{array}$ & $\begin{array}{c}-1.977 \\
(<0.001)^{* * *} \\
\end{array}$ & $\begin{array}{c}-1.986 \\
(<0.001)^{* * *}\end{array}$ & $\begin{array}{c}-1.945 \\
(<0.001)^{* * *} \\
\end{array}$ & $\begin{array}{c}-1.971 \\
(<0.001)^{* * *}\end{array}$ \\
\hline Number of observations & 2,574 & 2,574 & 2,574 & 2,430 & 2484 \\
\hline Number of subjects & 143 & 143 & 143 & 135 & 138 \\
\hline Log-likelihood & -1459.7 & -1457.8 & -1455.4 & -1370.8 & -1394.6 \\
\hline McFadden's pseudo-R2 & 0.109 & 0.110 & 0.112 & 0.163 & 0.149 \\
\hline AIC & 2931.3 & 2937.5 & 2932.9 & 2761.7 & 2809.2 \\
\hline
\end{tabular}

Note: This table reports the estimates of the coefficients and $p$-values in parentheses from different model specifications. $p$-values: $<0.001=* * *,<0.01=* *,<0.05=*,<0.1=\wedge$ 
Table A.4. Trade-offs fishers are willing to make between a reduction in bag limit by one lobster and a change in season length, maximum seasonal catch, minimum size limit for females, and penalties for non-compliant acts.

\begin{tabular}{llllllll}
\hline & All fishers & Potters & Divers & Multi & Low Avidity & Mid Avidity & High Avidity \\
\hline Season length & 3.80 & 4.46 & 3.83 & 2.87 & 4.40 & 3.54 & 2.65 \\
Max seasonal catch & 0.34 & 0.47 & 1.51 & -0.16 & 0.71 & 0.25 & -0.34 \\
Size limit for females & -0.73 & -0.61 & 0.09 & -1.09 & 0.54 & -1.42 & -2.88 \\
Increase in penalties & -9.96 & -10.16 & -6.60 & -11.40 & -15.11 & 21.10 & -30.99 \\
\hline
\end{tabular}

